\title{
Tolerance, Bone Mineral Content, and Serum Vitamin D Concentration of Term Infants Fed Partially Hydrolyzed Whey-based Infant Formula
}

\author{
Marlene W Borschel*,1 ${ }^{*}$, Sharon Groh-Wargo ${ }^{2}$, Bradford A Brabec ${ }^{3}$, Ekhard E Ziegler ${ }^{4}$, Richard E \\ Litov $^{5}$, Steven A Abrams ${ }^{6}$ and Jeffery S Oliver ${ }^{1}$ \\ ${ }^{1}$ Scientific \& Medical Affairs, Abbott Nutrition, Abbott Laboratories, Columbus, OH, USA \\ ${ }^{2}$ Case Western Reserve University at MetroHealth Medical Center, Departments of Pediatrics and Nutrition, Cleveland, \\ $\mathrm{OH}, \mathrm{USA}$ \\ ${ }^{3}$ Midwest Children's Health Research Institute, LLC, Lincoln, NE, USA \\ ${ }^{4}$ Fomon Infant Nutrition Unit, Department of Pediatrics, University of Iowa, Coralville, IA, USA \\ ${ }^{5}$ Pedia Research, LLC, Owensboro, KY, USA \\ ${ }^{6}$ Department of Pediatrics, USDA/ARS Children's Nutrition Research Center, Texas Children's Hospital and Baylor \\ College of Medicine, Houston, TX, USA
}

\begin{abstract}
The objective of the study was to assess the tolerance (intake, incidence of spit up/vomit, and stool patterns), bone mineral status, and vitamin D status of healthy, term infants fed one of two partially hydrolyzed bovine whey protein infant formulas from birth to 56 or 84 days of age. The control formula was commercially available and was compared to an experimental formula.

Eighty-nine term infants were enrolled in the study and 74 (83\%) completed the study. The control formula had similar vitamin D but lower calcium and phosphorus content and contained palm olein oil and lactose compared to the experimental formula. Infants fed the experimental formula exhibited significantly greater serum 25-OH vitamin D levels at 2 months of age, significantly greater bone mineral content as assessed by dual-energy x-ray absorptiometry at 3 months of age and softer stools during the study period compared to infants fed the control formula. No differences were observed between groups for formula intake, incidence of spit up/vomit, anthropometric measurements, or serum concentrations of calcium, phosphorus, skeletal alkaline phosphatase, or parathyroid hormone.

The results suggest that both study formulas are safe but differ in the metabolic response of infants fed the formula. Bone mineral content in these infants reflected differences in levels of nutrients important to calcium between two formulas over the short-term. Long-term implications and clinical relevance of these findings are unknown and require further study. These results provide additional knowledge regarding the typical vitamin D status as assessed by serum 25-OH vitamin D of healthy term formula-fed infants.
\end{abstract}

Keywords: Infant formula, vitamin D, infant feeding, bone mineral content, hydrolysate formula.

\section{INTRODUCTION}

Infant formulas based on partially hydrolyzed bovine milk proteins (pHF) are widely used. They account for about $22 \%$ of the infant formula marketed in the US [1]. Such formulas contain partially hydrolyzed whey proteins with or without hydrolyzed casein and the degree of protein hydrolysis ranges from about 8 to $20 \%$. The present study concerns a new formulation of a pHF that is whey-based but unlike other available pHF, has no added lactose, uses no palm olein oil as part of the fat source and contains higher levels of calcium $(\mathrm{Ca})$ and phosphorus $(\mathrm{P})$ than standard cow milk-based infant formulas.

\footnotetext{
*Address correspondence to this author at Abbott Nutrition, Abbott Laboratories, Dept 105670, RP3-2, 3300 Stelzer Road, Columbus, OH 43219, USA; Tel: 614-624-7578; Fax: 614-727-7578;

E-mail: marlene.borschel@abbott.com
}

The formula chosen as the control formula contained partially hydrolyzed bovine whey proteins as the protein source as well as $45 \%$ of the fat from palm olein oil. Formulas containing palm oil or palm olein oil as fat sources have been shown to result in reduced Ca absorption [2-4] and reduced bone mineral content (BMC) and bone mineral density (BMD) [5]. Additionally, unabsorbed fatty acids combine with unabsorbed Ca forming Ca-fatty acid soaps which result in firmer stools [6].

None of the aforementioned studies evaluated the impact of palm olein oil as ingredients in pHF. The present study was designed to assess stool patterns, intake, incidence of spit up/vomiting, and responses to questionnaire data as well as bone status assessed by BMC and BMD, and select serum measures of bone and vitamin D status. The new formula based on partially hydrolyzed bovine whey proteins was compared with a commercially available formula based on 
partially hydrolyzed bovine whey proteins. Both formulas were fed to healthy term infants from birth to two or three months of age.

\section{METHODS}

\section{Study Design and Subjects}

This was a controlled, randomized, double-blind, multicenter, parallel study. Term infants were enrolled between 0 and 8 days of age and studied to 56 or 84 days of age. Infants were randomly assigned to one of two study formulas, control formula (CF) or experimental formula (EF) which served as the sole source of nutrition. The study was designed to compare differences in BMC and BMD at 14 and 84 days of age; serum concentrations of $\mathrm{Ca}$, $\mathrm{P}$, skeletal alkaline phosphatase, parathyroid hormone, and 25-hydroxy vitamin D (25-OH D) at 56 days of age, and formula intake, incidence of spit-up/vomiting and stool patterns at 14, 28, 56 and 84 days of age. Weight, length, head circumference (HC) and their respective gains were assessed. Infants enrolled in the study were healthy singletons with a gestational age of 37-42 weeks and a birth weight $\geq 2490 \mathrm{~g}$ whose mothers had previously decided on formula feeding. Parents agreed to use the study formulas as the sole source of nutrition and to not administer any dietary supplements or medications. Written informed consent was obtained from a parent or legally authorized representative of each subject. Infants were to receive one of two study formulas (CF or EF) until 56 days of age at one site (BMC not assessed), and until 84 days of age at all other sites. A randomization schedule for each individual center was prepared, stratified by gender. Formula assignments were placed in sealed, numbered envelopes; at enrollment the next envelope for the stratification group was opened. Study formulas were identified by code only and study personnel, parents and caregivers were unaware of study formula identity. Both study formulas were packaged in a similar manner. Blinding was not broken until after all data had been collected. Subjects were recruited at five study sites located in Cleveland, OH; Lincoln, NE; Iowa City, IA; Owensboro, KY; and Houston, TX. The study protocol was reviewed and approved by Western Institutional Review Board, Olympia, WA (NE, KY, IA), the Institutional Review Board for Human Subject Research for Baylor College of
Medicine and Affiliated Hospitals, Houston, TX (TX), and the MetroHealth Institutional Review Board, Cleveland $\mathrm{OH}$ $(\mathrm{OH})$. This study was conducted in accordance with all applicable regulatory procedures, including Good Clinical Practices and the ethical principles originating from the Declaration of Helsinki. The identity of all study subjects was held in confidence.

\section{Study Formulas}

Both powdered study products met the levels of nutrients recommended for normal infants by the American Academy of Pediatrics (AAP) Committee on Nutrition [7], and as stipulated by the Infant Formula Act of 1980 [8] and subsequent amendments [9].

The CF used was Nestle Good Start ${ }^{\circledR}$ Supreme, docosahexaenoic acid (DHA)/arachidonic acid (ARA) powder (Glendale, CA); the EF was manufactured by Abbott Nutrition (AN), Abbott Laboratories (Columbus, OH). Both formulas were powdered and used similar levels of partially hydrolyzed cow's milk whey protein. While levels of fat and carbohydrate content were similar, the composition was different. The fat of the CF was provided by palm olein, soy, coconut, high-oleic (HO)-safflower and HO-sunflower oils; while that of the EF was provided by HO-safflower, soy, and coconut oils. Both formulas contained sources of ARA and DHA. Carbohydrate sources were lactose and corn maltodextrin for the CF and corn maltodextrin and sucrose for the EF. The vitamin D, Ca and P content of the two study formulas were analyzed at $\mathrm{AN}$, Columbus, $\mathrm{OH}$ after their respective expiration dates. The CF had less Ca (542 mg vs $869 \mathrm{mg} / \mathrm{L}$ ) and less P (315 mg vs $556 \mathrm{mg} / \mathrm{L}$ ) than the EF. The vitamin D3 content of study formulas was assessed by ultra performance liquid chromatography coupled with tandem mass spectrometry methodology validated at AN. Vitamin D content of the CF was similar to that of the EF (528 vs 541 IU vitamin D/L, respectively). Table 1 summarizes the composition of the study formulas.

\section{Study Assessments}

After enrollment, subjects had study visits at 14, 28, 56 and 84 days of age ( \pm 3 days) except for one site where subjects completed the study at 56 days due to inability of that

Table 1. Macronutrient Sources and Calcium, Phosphorus, and Vitamin D Content of Study Formulas

\begin{tabular}{|c|c|c|c|c|c|}
\hline $\begin{array}{l}\text { Study } \\
\text { Formula }\end{array}$ & & Macronutrient Source(s) & $\begin{array}{l}\text { Ca Content* } \\
\text { (mg/L) }\end{array}$ & $\begin{array}{l}\text { P Content* } \\
(\mathrm{mg} / \mathrm{L})\end{array}$ & $\begin{array}{c}\text { Vitamin } D^{*} \\
\text { Content (IU/L) }\end{array}$ \\
\hline \multirow[t]{3}{*}{$\mathrm{CF}$} & Protein & Partially hydrolyzed bovine whey & 542 & 315 & 528 \\
\hline & Carbohydrate & 79\% Lactose, 30\% Maltodextrin & & & \\
\hline & Fat & $\begin{array}{l}\text { 46\% Palm olein, } 26 \% \text { soy; } 20 \% \text { Coconut, } 6 \% \text { high oleic (HO)- } \\
\text { Safflower/HO-Sunflower Oils; } 0.64 \% \text { ARA, } 0.32 \% \text { DHA }\end{array}$ & & & \\
\hline \multirow[t]{3}{*}{$\mathrm{EF}$} & Protein & Partially hydrolyzed bovine whey & 869 & 556 & 541 \\
\hline & Carbohydrate & $80 \%$ Maltodextrin, 20\% Sucrose & & & \\
\hline & Fat & $\begin{array}{l}\text { 41\% HO-Safflower, } 29 \% \text { Soy, } 27 \% \text { Coconut oils, } 1.5 \% \text { mono- } \\
\text { and diglycerides; } 0.4 \% \text { ARA, } 0.15 \% \text { DHA }\end{array}$ & & & \\
\hline
\end{tabular}

*Analyzed Content. Label claim values for CF were $433 \mathrm{mg} \mathrm{Ca} / \mathrm{L}, 243 \mathrm{mg}$ P/L, and 406 IU vitamin D/L. 
site to assess BMC. Parents were instructed verbally and in writing on how to prepare feedings. They were given sufficient study formula at each study visit to feed their infant until the next study visit. Parents were asked to complete daily dietary intake records and stool records from enrollment to the Day 14 visit. At future study visits, such data were only recorded for the three days prior to the visit. Data collected included volume of formula consumed at each feeding, incidence of spit-up and vomiting associated with feedings, and characteristics of the infant's stools (frequency, consistency and color). Study site personnel reviewed these completed forms with the parents at each visit, confirmed that parents were compliant with the administration of no other foods, medicines, herbal products or home remedies, and elicited any information on adverse events or feeding intolerance. At each study visit, infant weight, length, and HC were assessed.

Infants underwent dual-energy $x$-ray absorptiometry (DXA) scans to determine bone mineral status at enrollment or Study Day 14 (or between 0 and 14 days of age) and at Study Day 84 ( \pm 5 days). Bone mineral content was not determined in 24 infants enrolled at one site. Bone mineral content and BMD were measured using a fan-beam DXA densitometer operated in the infant whole body mode. Instruments used included Hologic Delphi A (TX), Hologic Discovery (IA/KY), and Hologic QDR 4500 (OH) models. Various techniques to calm the infant for the procedure were utilized, such as feeding or rocking. Infants wore a diaper and were swaddled in a thin cotton blanket on the DXA scanning bed and infants were secured with a Velcro wrap. In the event of significant movement, up to two rescans were attempted. All infants were continuously observed by research personnel and no sedation was used. Each participating site sent unanalyzed scan data to the DXA coordinating center (Kenneth Ellis, PhD, Children's Nutrition Research Center, Houston, TX) for analysis using Hologic Version 12.1 software. Files were examined with all DXA images inspected for the presence of movement artifacts and interfering hardware. In the event that any atypical findings based on the DXA image were observed, any additional DXA scans (partial or whole body) of the infant obtained for the same visit were examined. In cases where the image anomaly could be easily identified and manipulated the observation was noted as part of the quality control of the scan image, and subsequent analyses were performed that accounted for the artifact. Of the scans completed, $2 \%$ were not useable, $7 \%$ represented the average of two scans, and $5 \%$ had movement artifacts that were either easily removed, or corrected by comparison to a second scan.

At the Day 56 visit a $1.0 \mathrm{~mL}$ blood sample was collected by venipuncture or heel stick at all sites. Care was taken to avoid hemolysis of the sample. Serum was analyzed for $\mathrm{Ca}$, $\mathrm{P}$, skeletal alkaline phosphatase, parathyroid hormone, and 25-OH D at a central laboratory (Heartland Assays, Inc., Ames, IA). Analysis for skeletal alkaline phosphatase, $\mathrm{P}$ and 25-OH D were given precedence in the event of a blood sample that was insufficient for the performance of all tests. Calcium and P levels were determined by spectrophotometric methods. Skeletal alkaline phosphatase was measured using a commercially available kit (Metra ${ }^{\circledR}$ BAP, Quindel Corporation, San Diego, CA). Intact parathyroid hormone was determined in serum by an immunoradiometric assay (Nichols Institute Diagnostics, San Clemens, CA). Concentration of 25-OH D was determined by radioimmunoassay [10]. This assay has an intra-assay coefficient of variation of $6 \%$ and an interassay coefficient of variation of $15 \%$.

\section{Statistical Methods}

The primary variable was mean rank stool consistency at 14 days of age. A sample size of 20 per group can be expected to detect a difference of 0.9 standard deviations with $80 \%$ power.

The analysis of evaluable data for a defined study outcome included data collected from all subjects following the study feeding protocol at the time of observation or assessment of the outcome. Exclusion from specific analyses of evaluable data included ingestion of vitamin/mineral supplements containing $\mathrm{Ca}$ or vitamin D (exclusion from blood chemistry, BMC and BMD analyses only), serum sample was hemolyzed (exclusion from serum vitamin $\mathrm{D}$ and $\mathrm{P}$ analyses only), and failure to have a valid DXA scan between 0 and 14 days of age and at Study Day 84 (exclusion from BMC and BMD analyses only).

Parents were required to complete daily stool records for their infants from enrollment to the Day 14 visit and thereafter for a three day period preceding the Study Day 28, 56 and 84 visits. In addition to information on the frequency of stooling and the color of the stools, parents were asked to record the consistency of each stool according to the following 5 point scale: watery $=1$, loose $/$ mushy $=2$, soft $=3$, formed $=4$, and hard $=5$. From these data, a mean rank stool consistency value was obtained as follows: the number of stools in each category for each day was multiplied by the category number and the resulting numbers were summed. This sum was then divided by the number of stools that day to provide the mean rank stool consistency for each day. These scores were then averaged over each study period. These mean rank stool consistency data were analyzed by analysis of variance (ANOVA) for the Day 14 data with treatment group and study center in the model and by repeated measures ANOVA for the Day 28, 56 and 84 data with treatment group, study day, treatment group by study day interaction, and study center in the model.

Analysis of variance was the statistical method used for comparability of groups at enrollment (birth weight, weight, length, and HC), with treatment group, gender, treatment group by gender interaction, and study center in the model. The Cochran-Mantel Haenzel analysis was used for assessing comparability at enrollment: for age at enrollment (raw mean scores differ test statistic) and for gender, race and ethnicity (general association test statistic). Weight, length, and HC data for Days 28, 56 and 84 were analyzed using a repeated measures analysis of covariance (ANCOVA) with treatment group, gender, treatment group by gender interaction, study day, treatment group by study day interaction, Day 14 measurement, and study center in the model. Gains in weight, length, and HC were analyzed using ANOVA with treatment group, gender, treatment group by gender interaction and study center in the model. 
The BMC and BMD data at Day 14 were analyzed using ANCOVA with treatment group, gender, treatment group by gender interaction, Day 14 weight, and study center in the model. The BMC and BMD data at Day 84 were also analyzed using ANCOVA with treatment group, gender, treatment group by gender interaction, Day 84 weight, Day 14 BMC (for BMC analysis) and BMD (for BMD analysis) measurements, and study center in the model. Blood biochemistry values were analyzed by ANOVA with treatment group and study center in the model.

Study results are generally shown as mean \pm the standard error of the mean (SEM) and are for the evaluable group unless otherwise noted. P-values from ANOVA, ANCOVA and repeated measures analyses are from the Type III sums of squares. P-values from the Wilcoxon rank-sum tests are from the two-sided normal approximation. All analyses were performed using SAS ${ }^{\circledR}$ Version 9.1.3 (SAS Institute, Cary, NC).

\section{RESULTS}

\section{Disposition of Study Subjects}

Eighty-nine subjects (44 CF and $45 \mathrm{EF}$ ) were enrolled across the five study sites $(27 \mathrm{OH}, 24 \mathrm{NE}, 22 \mathrm{IA}, 14 \mathrm{KY}, 2$ TX) and 74 subjects (83\%) completed the study protocol (Table 2). Of the 15 (8 CF and $7 \mathrm{EF}$ ) subjects who withdrew from the study, 2 CF subjects withdrew early and never received study formula; 7 subjects (4 CF and $3 \mathrm{EF}$ ) exited due to adverse events; 2 subjects ( $1 \mathrm{CF}$ and $1 \mathrm{EF}$ ) refused to take study product; $1 \mathrm{EF}$ subject exited without a reason given; 1 EF subject exited because the parents noticed some black particles due to scorching in the formula; and 2 subjects (1 $\mathrm{CF}$ and $1 \mathrm{EF}$ ) were lost to follow-up. There were no statistically significant differences observed between the two study groups at enrollment in regards to gender, race, age, weight, length, or HC.

\section{Stool Data - Stool Consistency}

Stool consistency data are shown in Table $\mathbf{3}$. There were statistically significant differences in mean rank stool consistency between the two study formula groups at all time points. Thus, infants fed EF had significantly softer stools than subjects fed CF. While stools of subjects fed CF were harder overall, there were no differences in the number of stools per day between the study groups (data not shown). Stool patterns for subjects in both study groups were generally within the range of what is seen among formula-fed infants.

\section{Formula Intake, Incidence of Spit-up and Vomiting, and Growth}

Table 3 shows formula intake (mL/d) for both groups. There were no statistically significant differences between the groups at any time point. Similarly, the average daily number of feedings and the incidence of spit-up/vomiting associated with feeding (data not shown) did not differ between groups. There were no statistically significant differences between the groups in regards to absolute weight, length, or HC at any study time point (data not shown) and no statistically significant differences between the groups in gains in weight, length, or HC from Day 14 to Day 84 (Table 4).

\section{Bone Mineralization and Body Fat}

Data on BMC, BMD and body fat composition are summarized in Table $\mathbf{5}$. Using body weight as a covariate, infants in the EF group had significantly greater mean BMC at Day 84 than infants fed CF, $117.2 \pm 4.5 \mathrm{~g}$ vs $110.8 \pm 4.4 \mathrm{~g}$, (mean \pm SEM), respectively (Least Squares Means $116.5 \pm 2.4 \mathrm{~g}$ and $110.4 \pm 2.5 \mathrm{~g}$, respectively; $\mathrm{p}=0.0407$ ). When weight was not used as a covariate, the difference in BMC at Day 84 was not significant. No statistically significant differences between groups were seen in BMD at Day 84. No significant differences were observed between groups at either Day 14 or Day 84 in total body fat or percent body fat.

\section{Biochemical Data}

The results of serum skeletal alkaline phosphatase, 25$\mathrm{OH} \mathrm{D}, \mathrm{P}, \mathrm{Ca}$, and parathyroid hormone assays are shown in Table 6. There were no statistically significant differences between infants fed CF and EF except that infants fed EF had significantly higher levels of 25-OH D than infants fed $\mathrm{CF}(31.0 \pm 0.9 \mathrm{ng} / \mathrm{mL}[77.5 \pm 2.3 \mathrm{nmol} / \mathrm{L}]$ vs. $27.2 \pm 0.7$ $\mathrm{ng} / \mathrm{mL}[67.8 \pm 1.8 \mathrm{nmol} / \mathrm{L}]$, respectively) at Study Day 56 $(\mathrm{p}=0.0020)$.

A post-hoc analysis was performed to correlate the serum parathyroid hormone values with the serum $25-\mathrm{OH}$ vitamin D levels for subjects in both study groups. A significant inverse correlation between these two variables was observed: $\mathrm{r}=-0.357 ; \mathrm{p}=0.004(\mathrm{n}=63)$.

\section{DISCUSSION}

The present study was designed to assess formula tolerance and stool characteristics as well as measures of bone and vitamin D status in infants fed a newly developed or a commercially available formula which were both based on partially hydrolyzed bovine whey proteins.

No formula tolerance issues of concern were detected in the present study. While the stool consistencies for all subjects were within the range of expected values, infants who ingested the palm olein oil containing CF had significantly firmer stools throughout the study compared with infants fed EF. In our experience, differences in mean rank stool consistency between groups of 0.3 to 0.5 are noticeable by parents even if the differences are not statistically different. These results were in agreement with reports of harder stools in infants receiving palm olein oil formulas based on intact bovine milk proteins $[6,11]$. The current study confirms these earlier findings and extends the observation to formulas based on partially hydrolyzed whey proteins.

No attempt was made to control for the intakes of $\mathrm{Ca}, \mathrm{P}$, or vitamin $\mathrm{D}$. Nonetheless, the BMC and serum vitamin $\mathrm{D}$ differences found in this study may provide useful insight into key nutritional factors that influence infant bone status. Infants fed the EF received a similar amount of vitamin D but $60 \%$ more $\mathrm{Ca}, 76 \%$ more $\mathrm{P}$ than infants fed the $\mathrm{CF}$. While infants in both groups demonstrated appropriate growth, a statistically significant greater BMC difference 
Table 2. Characteristics and Disposition of All Enrolled Study Subjects (All Subjects) and the Subject Cohort with DXA Assessment Data at Study Day 84 (DXA Cohort)

\begin{tabular}{|c|c|c|c|c|}
\hline Subject Information & & $\mathbf{C F}$ & $\mathbf{E F}$ & Total \\
\hline \multicolumn{5}{|l|}{ Enrolled Subjects, N } \\
\hline & DXA cohort & 24 & 24 & 48 \\
\hline \multicolumn{5}{|l|}{ Subjects Completing Study Protocol, N (\%) } \\
\hline & DXA cohort & $24(100)$ & $24(100)$ & $48(100)$ \\
\hline \multicolumn{5}{|l|}{ Subjects Withdrawing from Protocol, N (\%) } \\
\hline & All subjects & $8(18)$ & $7(16)$ & $15(17)$ \\
\hline & DXA cohort & $0(0)$ & $0(0)$ & $0(0)$ \\
\hline \multicolumn{5}{|l|}{ Gender, \% Male/Female } \\
\hline & DXA cohort & $67 / 33$ & $58 / 42$ & - \\
\hline \multicolumn{5}{|c|}{ Race, \% White/Black or African-American/Other } \\
\hline & All subjects & $68 / 20 / 11$ & $67 / 24 / 9$ & - \\
\hline & DXA cohort & $63 / 29 / 8$ & $63 / 25 / 13$ & - \\
\hline \multicolumn{5}{|l|}{ Age at Enrollment, days } \\
\hline & All subjects & $5.4 \pm 0.3(44)^{*}$ & $5.5 \pm 0.3(45)$ & - \\
\hline & DXA cohort & $5.8 \pm 0.4(24)$ & $5.7 \pm 0.4(24)$ & - \\
\hline \multicolumn{5}{|l|}{ Weight at Enrollment, g } \\
\hline & DXA cohort & $49.5 \pm 0.3(24)$ & $49.9 \pm 0.4(24)$ & - \\
\hline \multicolumn{5}{|l|}{ HC at Enrollment, cm } \\
\hline & All subjects & $35.0 \pm 0.2(44)$ & $35.1 \pm 0.2(45)$ & - \\
\hline & DXA cohort & $35.0 \pm 0.2(24)$ & $35.1 \pm 0.2(24)$ & - \\
\hline
\end{tabular}

was noted at 3 months of age and higher serum 25-OH vitamin D concentrations at 2 months of age in infants fed the EF compared to those fed the CF.

The differences in BMC in the current study are similar to those reported by Specker et al. [12] and could be due to multiple factors, most obviously the differences in $\mathrm{Ca}$ and $\mathrm{P}$ content. It is unknown if the findings of the present study are clinically relevant but the difference may become even wider between groups if formula feeding were extended to 12 months of age as is recommended by AAP for infants who are not breastfed [13]. A recent study by Pirilä et al. [14] reported on the association between infant feeding practices and bone health at 32 years of age. Males who received $\leq 3$ months of breastfeeding and thus longer formula-feeding resulting in higher $\mathrm{Ca}$ and $\mathrm{P}$ intakes during infancy, had significantly greater BMC, bone mineral density and bone area at 32 years of age compared to those receiving $\geq 7$ months of breastfeeding. All subjects in the Pirilä et al study received 1000 IU of vitamin D daily during infancy. The results suggest that infant feeding pattern differences like different $\mathrm{Ca}$ and P intakes could have long-lasting effects on BMC. Further studies are needed to confirm these findings. Of interest, in the present study, the presence of lactose in the CF did not compensate for the lower $\mathrm{Ca}$ and $\mathrm{P}$ content of the CF com- 
Table 3. Mean Rank Stool Consistency and Mean Study Formula Intakes of Infants Fed Study Formula at 14, 28, 56 and 84 Days of Age

\begin{tabular}{|l|l|l|}
\hline \multicolumn{1}{|c|}{ Parameter } & \multicolumn{1}{|c|}{ CF } & \multicolumn{1}{|c|}{ EF } \\
\hline \hline Mean Rank Stool Consistency* & & $2.63 \pm 0.09(41) \ddagger$ \\
\hline Day 14 & $3.06 \pm 0.08(40) \dagger$ & $2.30 \pm 0.13(39) \S$ \\
\hline Day 28 & $3.02 \pm 0.11(39)$ & $2.19 \pm 0.12(38) \S$ \\
\hline Day 56 & $2.81 \pm 0.08(37)$ & $2.46 \pm 0.16(28) \S$ \\
\hline Day 84 & $2.80 \pm 0.08(26)$ & \\
\hline Formula Intake, mL/day & & $613 \pm 29(40)$ \\
\hline Day 14 & $541 \pm 18(40)$ & $803 \pm 35(39)$ \\
\hline Day 28 & $714 \pm 24(39)$ & $872 \pm 39(39)$ \\
\hline Day 56 & $849 \pm 33(37)$ & $954 \pm 73(28)$ \\
\hline Day 84 & $871 \pm 35(26)$ & \multicolumn{1}{|c|}{ (3) } \\
\hline
\end{tabular}

*Mean rank stool consistency calculated as 1=watery, 2=loose/mushy, 3=soft, 4=formed, 5=hard. Higher scores indicate firmer stools.

$\dagger$ Values are mean \pm SEM $(\mathrm{N})$.

$\ddagger$ Significant difference EF $<$ CF $(p=0.0005)$

$\S$ Significant difference EF $<$ CF $(p<0.0001)$

Table 4. Mean Weight Gain, Length Gain and Head Circumference Gain of Male and Female Study Subjects Fed Study Formula between 14 and 84 Days of Age

\begin{tabular}{|c|c|c|c|}
\hline Parameter & & CF & $\mathbf{E F}$ \\
\hline \multicolumn{4}{|l|}{ Weight Gain, g/day } \\
\hline & Males & $34.2 \pm 1.9(16)^{*}$ & $32.9 \pm 1.4(17)$ \\
\hline & Females & $30.9 \pm 1.9(10)$ & $30.8 \pm 1.6(11)$ \\
\hline \multicolumn{4}{|l|}{ Length Gain, cm/day } \\
\hline & Males & $0.11 \pm 0.0(16)$ & $0.11 \pm 0.0(17)$ \\
\hline & Females & $0.11 \pm 0.0(10)$ & $0.12 \pm 0.0(11)$ \\
\hline \multicolumn{4}{|c|}{ Head Circumference Gain, cm/day } \\
\hline & Males & $0.07 \pm 0.0(16)$ & $0.06 \pm 0.0(17)$ \\
\hline & Females & $0.06 \pm 0.0(10)$ & $0.07 \pm 0.0$ \\
\hline
\end{tabular}

*Values are mean \pm SEM $(\mathrm{N})$

pared to the EF. Lactose has been demonstrated to enhance Ca absorption in infants $[15,16]$.

In addition to the lower $\mathrm{Ca}$ and $\mathrm{P}$ content, the presence of palm olein oil in the CF may have contributed also to bring about the decreased BMC observed in infants fed that formula. The difference in BMC at 3 months of age, is consistent with BMC differences noted at 3 months of age between palm olein oil-free and palm olein oil-containing formula groups in other studies [5,17].

It is unknown whether the statistically significantly difference in 25-OH D values seen at 2 months of age is clinically relevant. Recently, the Institute of Medicine [18] concluded that average blood levels of vitamin D above 20 $\mathrm{ng} / \mathrm{mL}(50 \mathrm{nmol} / \mathrm{L})$ are sufficient for good bone health in most individuals and there are insufficient scientific data at present to warrant an increase in optimal serum vitamin $\mathrm{D}$ levels higher than $20 \mathrm{ng} / \mathrm{mL}(50 \mathrm{nmol} / \mathrm{L})$. All but one of the evaluable infants in the current study maintained serum 25$\mathrm{OH}$ D levels $\geq 20 \mathrm{ng} / \mathrm{mL}(50 \mathrm{nmol} / \mathrm{L})$; one infant had a serum $25-\mathrm{OH} \mathrm{D}$ concentration of $18.4 \mathrm{ng} / \mathrm{mL}$ (46 nmol/L). It has been proposed [19] that 25-OH D concentrations $<20$ $\mathrm{ng} / \mathrm{mL}(50 \mathrm{nmol} / \mathrm{L})$ rather than $10 \mathrm{ng} / \mathrm{mL}(25 \mathrm{nmol} / \mathrm{L})$ are considered indicative of vitamin $\mathrm{D}$ deficiency, and that optimal levels are $\geq 30 \mathrm{ng} / \mathrm{mL}(75 \mathrm{nmol} / \mathrm{L})$. A greater percentage of infants fed the EF (66\%) than those fed the CF (29\%) had $25-\mathrm{OH} \mathrm{D}$ values $\geq 30 \mathrm{ng} / \mathrm{mL}$ (75 nmol/L). Of note, mean formula intakes, though not statistically significantly different, were slightly higher for the EF-fed infants at each study visit. This difference in volume intake may have contributed to the finding of significantly higher serum 25-OH D levels in the EF group. 
Table 5. Bone Mineral Content (BMC), Bone Mineral Density (BMD), and Body Fat (g and \%) of Infants fed Study Formula at 14 and 84 Days of Age

\begin{tabular}{|c|c|c|c|}
\hline Variable & & CF & EF \\
\hline & & $(n=24)$ & $(n=24)$ \\
\hline \multicolumn{4}{|l|}{ BMC, $\mathbf{g}$} \\
\hline & Day 14 & $66.6 \pm 1.8^{*}$ & $70.8 \pm 2.7$ \\
\hline & Day 84 & $110.8 \pm 4.4$ & $117.2 \pm 4.5 \dagger$ \\
\hline \multicolumn{4}{|l|}{$\mathrm{BMD}, \mathrm{g} / \mathrm{cm}^{2}$} \\
\hline & Day 14 & $0.198 \pm 0.003$ & $0.207 \pm 0.004$ \\
\hline & Day 84 & $0.220 \pm 0.005$ & $0.227 \pm 0.005$ \\
\hline \multicolumn{4}{|l|}{ Body Fat, $g$} \\
\hline & Day 14 & $403 \pm 30$ & $429 \pm 34$ \\
\hline & Day 84 & $1723 \pm 114$ & $1573 \pm 94$ \\
\hline \multicolumn{4}{|l|}{ Body Fat, \% } \\
\hline & Day 14 & $10.7 \pm 0.7$ & $11.2 \pm 0.8$ \\
\hline & Day 84 & $27.0 \pm 1.3$ & $25.1 \pm 1.1$ \\
\hline
\end{tabular}

* Values are mean \pm SEM

$\dagger$ Significant difference EF > CF, p=0.0407. ANCOVA (Treatment group, gender, treatment group by gender interaction, Day 84 weight, Day 14 BMC and study center were factors).

Table 6. Serum Biochemistries of Infants Fed Study Formula at 56 Days of Age

\begin{tabular}{|l|l|l|}
\hline \multicolumn{1}{|c|}{ Serum Parameter } & \multicolumn{1}{c|}{ CF } & \multicolumn{1}{c|}{ EF } \\
\hline \hline Serum Ca, mmol/L & $2.61 \pm 0.02(37)^{*}$ & $2.63 \pm 0.02(37)$ \\
\hline Serum P, mmol/L & $1.93 \pm 0.04(31)$ & $1.95 \pm 0.03(32)$ \\
\hline Serum Skeletal Alkaline Phosphatase, U/L & $206 \pm 9(37)$ & $188 \pm 9(37)$ \\
\hline Serum Parathyroid Hormone, pg/mL & $27.8 \pm 1.6(34)$ & $29.2 \pm 2.2(37)$ \\
\hline Serum 25-OH Vitamin D, nmol/L & $67.8 \pm 1.8(31)$ & $77.5 \pm 2.3(32) \dagger$ \\
\hline
\end{tabular}

* Values are mean \pm SEM $(\mathrm{N})$

$\dagger$ Significant difference $\mathrm{EF}>\mathrm{CF}, \mathrm{p}=0.0020$

In agreement with the results of studies in adolescents [20,21], a significant inverse relationship was observed between serum 25-OH D and serum parathyroid hormone concentration. Increases in serum parathyroid hormone concentrations can contribute to bone resorption, osteoporosis and fractures [22]. In adults [22] and adolescents [21], serum parathyroid hormone concentration appears to stabilize when concentrations of 25-OH D are sufficient.

The 25-OH D data observed in this study are of interest in regards to the recent debate on possible vitamin D deficiency in infants and children $[19,23,24]$. In 2008, the AAP recommended that all infants and children receive a minimum daily intake of $400 \mathrm{IU}$ of vitamin D, beginning in the first few days after birth [25] and recommended supplementation for infants who are breastfed or formula-fed who ingest less than $1 \mathrm{~L}$ of formula/day. In 2010, the Institute of Medicine recommended average intakes of 400 IU vitamin
D/day for infants [18]. Perrine et al [26] recently reported that only 24.8 to $34.9 \%$ of formula-fed infants have vitamin $\mathrm{D}$ intakes from formula and supplements that meet the current recommended intake of at least $400 \mathrm{IU}$ vitamin $\mathrm{D} /$ day. The AAP has suggested that infants drink no more than $32 \mathrm{fl}$ oz $(960 \mathrm{~mL})$ of formula per day [27]. The maximum vitamin D content of infant formula allowed per the Infant Formula Act $[8,9]$ is $100 \mathrm{IU} / 100 \mathrm{kcal}$ (676 IU vitamin D/L of 20 $\mathrm{kcal} / \mathrm{fl}$ oz formula). All infant formulas in the US must not exceed the Infant Formula Act maximum and meet the stated label claim minimum at the end of shelf life. Vitamin D is a labile nutrient with variable stability in different formulas, types of containers, and under different storage conditions. Thus, it was not surprising that the formulas in this study had actual vitamin D contents of $>500 \mathrm{IU} / \mathrm{L}$ and label claim content of $406 \mathrm{IU} / \mathrm{L}$. Increasing the vitamin D label claim of an infant formula increases the risk for manufacturers of ex- 
ceeding the upper allowed level, since there is a stringent maximum vitamin D content designated by the Infant Formula Act. Considering the current Infant Formula Act maximum for vitamin D content and the overages of vitamin D required to meet label claim at end of shelf life, there is a small window available for manufacturers of infant formulas in the US to provide much more vitamin $\mathrm{D}$ on average than did the present study formulas, both of which contained $>500$ IU vitamin D/L after expiration. Presently, the highest vitamin D label claim for an infant formula in the US is 507 IU/L (75 IU/100 kcal) for a newborn formulation designed for feeding the first 3 months of life. With the current Infant Formula Act vitamin D maximum, it is not likely possible to significantly increase the serum vitamin D levels of US formula-fed infants higher than those observed in the present study, except through the use of additional vitamin D supplements given directly to the infant.

\section{CONCLUSION}

In conclusion, the present study of two formulas based on partially hydrolyzed bovine whey proteins suggests that these formulas are safe, but differ in the metabolic response of infants fed the formulas. The CF had similar vitamin D but lower Ca and P content and contained palm olein oil and lactose. Infants fed the EF from the first week in life exhibited significantly greater serum 25-OH vitamin D levels at 2 months of age, significantly greater BMC at 3 months of age and softer stools throughout the study compared to infants fed the CF. Bone mineral content in study infants reflected differences in levels of nutrients ( $\mathrm{Ca}, \mathrm{P}$ ) between the formulas over the short-term. It would be of interest to evaluate further the infant's apparent metabolic adaptability to shortterm differences in the intake of key nutrients. The long-term implications and clinical relevance of these findings are unknown and require further study. These results provide additional knowledge regarding the typical vitamin D status as assessed by serum 25-OH D of healthy term formula-fed infants.

\section{LIST OF ABBREVIATIONS}

$\begin{array}{ll}\text { AAP } & =\text { American Academy of Pediatrics } \\ \text { AN } & \text { Abbott Nutrition } \\ \text { ANCOVA } & =\text { Analysis of covariance } \\ \text { ANOVA } & =\text { Analysis of variance } \\ \text { ARA } & =\text { Arachidonic acid } \\ \text { BMC } & =\text { Bone mineral content } \\ \text { BMD } & =\text { Bone mineral density } \\ \text { Ca } & =\text { Calcium } \\ \text { CF } & =\text { Control formula } \\ \text { DHA } & =\text { Docosahexaenoic acid } \\ \text { DXA } & =\text { Dual-energy x-ray absorptiometry } \\ \text { EF } & =\text { Experimental formula } \\ \text { HC } & =\text { Head circumference } \\ \text { HO } & =\text { High-oleic }\end{array}$

$\mathrm{P}$

$\mathrm{pHF} \quad=$ Partially hydrolyzed milk protein formula

SEM $=$ Standard error of the mean

25-OH D = 25-hydroxy vitamin $\mathrm{D}$

\section{CONFLICT OF INTEREST}

This study was funded by AN, Abbott Laboratories. Two authors (MWB and JSO) are employees of AN, Abbott Laboratories. Authors (EEZ, SGW, BAB) receive research funding from AN and other infant formula companies (EEZ) and speak at programs sponsored by AN (SGW).

\section{ACKNOWLEDGEMENTS}

The authors would like to thank Kenneth Ellis, $\mathrm{PhD}$ and Roman Shypailo at the Children's Nutrition Research Center, Houston, Texas for their assistance in site training and interpretation of the DXA results. We also thank Janice Fonarow, RD who served as the study monitor and coordinated implementation of the study, Mary Alice Springer for assistance with preparation of the manuscript, and John Lasekan, $\mathrm{PhD}$ who contributed to the design of the study and assisted with preparation of the manuscript. Lastly, we would like to recognize the parents and infants who participated in this trial.

\section{FUNDING STATEMENT}

The clinical study and manuscript preparation were funded by Abbott Nutrition, Abbott Laboratories, Columbus, Ohio.

\section{REFERENCES}

[1] Nielson FDMx Available from: http://www.nielsen.com/us/en. html. [Accessed 2011 Dec 5].

[2] Ostrom KM, Borschel MW, Westcott JE, Richardson KS, Krebs NF. Lower calcium absorption in infants fed casein hydrolysateand soy protein-based infant formulas containing palm olein versus formulas without palm olein. J Am Coll Nutr 2002; 21: 564-9.

[3] Nelson SE, Rogers RR, Frantz JA, Ziegler EE. Palm olein in infant formula: absorption of fat and minerals by normal infants. J Am Clin Nutr 1996; 64: 291-6.

[4] Nelson SE, Frantz JA, Ziegler EE. Absorption of fat and calcium by infants fed a milk-based formula containing palm olein. J Am Coll Nutr 1998; 17: 327-32.

[5] Koo WWK, Hammami M, Margeson DP, et al. Reduced bone mineralization in infants fed palm olein-containing formula: A randomized, double-blinded, prospective trial. Pediatrics 2003;111: 1017-23.

[6] Quinlan PT, Lockton S, Irwin J, Lucas AL. The relationship between stool hardness and stool composition in breast- and formulafed infants. J Pediatr Gastroenterol Nutr 1995; 20: 81-90.

[7] American Academy of Pediatrics, Committee on Nutrition. Commentary on breast feeding and infant formulas, including proposed standards for formulas. Pediatrics 1976; 57: 278-85.

[8] Infant Formula Act of 1980. Public Law 96-359, 26 September 1980.

[9] Infant Formula Act Amendments, 21 Code of Federal Regulations (As Amended), [412] sec. 350a. Infant Formulas, 27 October 1986.

[10] Hollis BW, Kamerud JQ, Selvaag SR, Lorenz JD, Mapoli JL. Determination of vitamin D status by radioimmunoassay with an 125 I-labelled tracer. Clin Chem 1993; 39: 529-33.

[11] Lloyd B, Halter RJ, Kuchan MJ, et al. Formula tolerance in postbreastfed and exclusively formula-fed infants. Pediatrics [serial online] 1999;103:e7. Available at: http://www.pediatrics.org/cgi/ content/full/103/1/e7 (accessed 28 September 2011). 
[12] Specker BL, Beck A, Kalkwarf H, Ho M. Randomized trial of varying mineral intake on total body bone mineral accretion during the first year of life. Pediatrics [serial online] 1997; 99; e12. Available at : http://www.pediatrics.org/cgi/content/full/99/6/e12 [accessed 6 August 2011].

[13] Kleinman RE, Ed. Pediatric nutrition handbook. $6^{\text {th }}$ ed. Elk Grove Village: American Academy of Pediatrics 2009.

[14] Pirilä S, Taskinen M, Viljzkainen H, et al. Infant milk feeding influences adult bone health: a prospective study from birth to 32 years. PLoS One [serial online] 2011; 6: e19068. Available at: http://www.plosone.org/article/info\%3Adoi\%2F10.1371\%2Fjourna l.pone.0019068 (accessed 5 December 2011).

[15] Abrams SA, Griffin IJ, Davila PM. Calcium and zinc absorption from lactose-containing and lactose-free infant formulas. Am J Clin Nutr 2002; 76: 442-6.

[16] Ziegler EE, Fomon SJ. Lactose enhances mineral absorption in infancy. J Pediatr Gastroenterol Nutr 1983; 32: 288-94.

[17] Kennedy K, Fewtrell MS, Morley R, et al. Double-blind, randomized trial of a synthetic triacylglycerol in formula-fed term infants: effects on stool biochemistry, stool characteristics, and bone mineralization. Am J Clin Nutr 1999; 70: 920-7.

[18] Institute of Medicine. Dietary reference intakes for calcium and Vitamin D. Washington, DC:National Academies Press 2011.

[19] Gordon CM, Feldman HA, Sinclair L, et al. Prevalence of vitamin D deficiency among healthy infants and toddlers. Arch Pediatr Adolesc Med 2008; 162; 505-12.
[20] Gordon CM. DePeter KC, Feldman HA, Grace E, Emans SJ. Prevalence of vitamin D deficiency among healthy adolescents. Arch Pediatr Adolesc Med 2004; 158: 531-7.

[21] Hill TR, Cotter AA, Mitchel S, et al. Vitamin D status and parathyroid hormone relationship in adolescents and its association with bone health parameters: analysis of the Northern Ireland Young Heart's Project. Osteoporos Int 2010; 21: 695-700.

[22] Lips P. Vitamin D physiology. Prog Biophys Mol Biol 2006; 92: 48.

[23] Mansbach JM, Ginda AA, Camargo CA. Serum 25-hydroxyvitamin $D$ levels among US children aged 1 to 11 years: do children need more vitamin D? Pediatrics 2009;124: 1404-10.

[24] Hollis BW, Lowery JW, Pittard WB, Guy DB, Hansen JW. Effect of age on the intestinal absorption of Vitamin $\mathrm{D}_{3}$-palmitate and nonesterified Vitamin $D_{2}$ in the term human infant. J Clin Endocrinod Metab 1996; 81: 1385-8.

[25] Wagner CL, Greer FR. Section on Breastfeeding and Committee on Nutrition. Prevention of rickets and vitamin D deficiency in infants, children, and adolescents. Pediatrics 2008; 122: 1142-52.

[26] Perrine CG, Sharma AJ, Jefferds MED, Serdula MK, Scanlon KS. Adherence to vitamin D recommendations among US infants. Pediatrics 2010; 125: 627-32.

[27] American Academy of Pediatrics. Feeding your baby: Breast and bottle. In: Shelov SP, Altman TR, Eds. Caring for your baby and young child: birth to age $5.5^{\text {th }}$ ed. New York: Bantam Books 2009; pp. 79-124.

Received: December 20, 2011

Revised: March 23, 2012

Accepted: March 26, 2012

(C) Borschel et al.; Licensee Bentham Open

This is an open access article licensed under the terms of the Creative Commons Attribution Non-Commercial License (http://creativecommons.org/licenses/by-nc/3.0/) which permits unrestricted, non-commercial use, distribution and reproduction in any medium, provided the work is properly cited. 